termed incompressible and those termed compressible. To a first approximation the dividing line can be drawn so that we find on the side of the incompressible materials fine- and coarse-grained types which are wholly in the condensed states, that is, solid, liquid or intermediate, while on the side of the compressible materials we find the types which are wholly or partly in gaseous states. The division is particularly interesting for the shear-elastic class, in which we find that the types of fine-grained materials considered, namely, the colloidal solutions, are wholly condensed and thus incompressible, whereas the coarse-grained types of rubber sponges and fibrous assemblies contain gases (air) and are accordingly compressible.

On the basis of the classification given above, we can predict in a qualitative way the behaviour under various conditions of the materials within one class and division. We shall illustrate these predictions by describing for the coarse- and the fine-grained materials of the same class experiments under conditions chosen first so that all the materials behave alike because of their class resemblance in shear elasticity ${ }^{1,3}$, and secondly, so that they behave differently on account of the additional complications caused by the differences in compressibility.

In the experiments illustrated in Fig. 3, an upright cylindrical specimen of the material considered was subjected to torsion between two parallel disks, the lower one fixed in height but capable of rotation, and the upper one free to move up and down but prevented from rotating. This was achieved by mounting the lower disk on top of a pulley, and securing the upper disk to a stem which slides in a sleeve and carries a crossbar which is checked by the supporting frame. The cylindrical wall of the specimen was left open to the atmosphere. Experiments were performed with various materials including liquids, fibrous assemblies and rubber sponges, but only the shear-elastic materials are shown since the others produce effects of a merely trivial kind. To apply the torsion it is necessary that the material should stick to the disk. For the liquid no special measures are required, but for the fibres it is necessary to face the disks with glass paper, and the sponges must be secured by cementing (thanks are due to Messrs. Dunlop Rubber Co., Expanded Rubber Co., and B.B. Chemical Co., who supplied us with a wide range of sponges, expanded rubbers and adhesives). The photographs show the results of the application of torsion. The pointer on the left-hand side of a picture indicates the original height of the top disk by pointing to the original position either of the crossbar, or of the hand of the dial-gauge.

The first row shows three pictures referring respectively to a fine-grained material, namely, a colloidal solution, and to two coarse-grained materials, namely, a fibrous assembly and a sponge with a closed structure. The materials are subjected to torsion while at the same time they are compressed by a weight. Under these conditions the materials develop stresses which drive them inwards to such an extent as to push the top disk upwards against the action of the weight. The amount by which the top disk rises differs in the three cases, being greatest for the colloidal solution, less for the fibrous assembly and so small for the sponge as to require a dial gauge to reveal it. For the colloidal solution, the torsional motion has to be maintained at constant velocity during the exposure, as otherwise the liquid would lose its stress and run out of the gap. (It is particu- larly striking that the stresses hold this material in place despite the opposing influence of gravitational and centrifugal forces.) On the other hand, the sponge is a solid which is subjected to a static torsion. The fibrous assembly can be treated as a solid or a liquid, and the torsion applied statically or dynamically.

The second row of pictures shows a visco-elastic liquid and a fibrous assembly. The arrangements are similar to those used for the previous experiments, except that now the speeds and other conditions of the experiment are so chosen that a disturbance occurs in the form of an eddy which rolls the material up and then ejects it from the gap. The photographs were taken at the instant of ejection. No exact theory has yet been developed to account fully for this phenomenon, which occurs exceptionally in liquids but commonly in the fibrous assemblies; it was first observed by K. Weissenberg and R. J. Russell on some specially prepared visco-elastic liquids.

All the photographs so far discussed show the similarity between the coarse- and fine-grained materials. By contrast, the third row shows the additional complication produced in the coarsegrained materials because of their compressibility. The specimens are a fibrous assembly, an open sponge and a closed sponge, in all cases cemented to the disk and treated as solids. A statical torsion has been applied; but in this case without weighing down the top plate. All the materials are again drawn inwards, but the upper disk is pulled down, that is, in the opposite sense to that shown before. It is evident that the materials have been reduced in volume by the waisting and reduction in height.

From the experimental observations eited, it may be concluded that a wide range of structures of cellular or fibrous type provide possible models for the hidden molecular structure of the apparently continuous colloidal solutions in the shear-elastic class. Such models would be insufficiently resistant to changes in volume, and it would be necessary to provide for the missing resistance by appropriate assumptions.

Thanks are due to the director of the Shirley Institute for giving us the opportunity to carry out this work and permission to publish it. We are indebted to Mr. C. Bradley and Miss J. Gallagher for the photographs accompanying this article.

${ }^{1}$ Freeman, S. M., and Weissenberg, K., Nature, 161, 324 (1948).

2 Thomson, Sir W., "Math. and Phys. Papers", III, XCII, Part 1, 34 ${ }^{3}$ Weissenberg, K., Nature, 159, 310 (1947).

\section{BRITISH ASSOCIATION BRIGHTON MEETING}

$T$ HE programme for the 110th Annual Meeting of the British Association for the Advancement of Science has now been published. The meeting will be held in Brighton during September 8-15, under the presidency of Sir Henry Tizard, who will deliver an address on "The Passing World" in which he will review some of the outstanding features of the progress of science and technology in Great Britain from the close of a period of stagnation towards the end of the nineteenth century.

The meeting will be held, as usual, in thirteen concurrent sections with a number of joint sessions, and the programme also includes evening discourses and a session of the Division for Social and Inter- 
national Relations of Science, at which Dr. Julian Huxley and others from Unesco will discuss "Science Across the Frontiers".

The sectional programmes contain a wide variety of topics, ranging from cosmic magnetism to the effects of the cinema on young people. The objects of the annual meetings of the Association being to provide opportunities for men of science to meet each other and discuss their work in the setting of science as a whole, to allow men of science and laymen to meet each other, and to increase the public understanding of science, the programme includes both specialist and general topics (nearly three hundred speakers).

Among the former are sessions on recent advances in the crystalline state, opened by Sir Lawrence Bragg, geology and air photography, functional morphology (including an address by Prof. $\mathbf{H}$. Graham Cannon), the denudation of the weald, applicable mathematics, the case for and against the metric system, transmission of effects from the endings of nerve fibres (opened by Sir Henry Dale), recent advances in colour vision (including an address by Prof. H. Hartridge), to mention only a few.

The more general topics include industrial applications of electronic devices (with exhibition), new metals in industry, new building materials, problems of Colonial development, movements of population, fuel economy with special reference to the heat pump, human blood groups, problems of old age. Various aspects of food and nutrition will be discussed at several sessions arranged by the Sections of Zoology, Economics, Physiology, Agriculture and Chemistry, and the programme also includes discussions and talks on seience in industry as arranged by no fewer than seven sections.

Arrangements have been made for sixty excursions and a number of social engagements, and the members will be entertained at a civic reception in the buildings on the Royal Pavilion Estate.

Further details of the meeting may be obtained from the Secretary of the British Association, Burlington House, London, W.1 (Regent 2019). There is no closing date for registration, and hotel accommodation is still available in Brighton.

\section{THE SWEDISH DEEP-SEA EXPEDITION}

\section{BY PROF. HANS PETTERSSON Göteborg}

$\mathrm{A}^{\mathrm{N}}$ $\mathrm{N}$ account has already been given of the first part of the cruise of the Albatross (see Nature, October 25, 1947, p. 559). On August 27, 1947, the Albatross started from Balboa on its cruise across the Pacific Ocean, and five months later terminated it in the idyllic harbour of Ternate, visited by the Challenger Expedition seventy-three years earlier. The course led first to the Galapagos Islands, where the upwelling cold water and the deposits beneath it were studied; then along a west-north-west direction until the eighteenth parallel was reached, from there turning south for Nukuhiva and for Tahiti. Between Tapeete and Honolulu the course of the Challenger was followed, although to the opposite direction, several of its stations being repeated under way. From Honolulu the course lay to the south-southwest and, after crossing the equator for a fourth time, we steered west-north-west, finally reaching the great deeps south-east of Mindanao.

Our four first crossings of the counter-equatorial current were used for a close study of its hydrography by frequent deep series, intercalated by bathythermograph shots through the uppermost 140 metres. Interesting results are shown by our diagrams, as the signs of upwelling and descending water in the regions of divergence and convergence respectively in the surface. A distinct oxygen minimum extended from a few hundred metres downwards for $800 \mathrm{~m}$. or more. Clouds of suspended particles studied by the Tyndall method were met with also at great depths.

The ruggedness of the sea bottom revealed by our echograms often proved an obstacle to coring operations, as were also the not infrequent encounters with hard bottom (lava beds) at great depths, sometimes leading to partial or total loss of the steel coring tubes. Nevertheless, fifty-seven cores, varying in length from a few metres to fifteen metres, were raised from depths between 2,000 and nearly $8,000 \mathrm{~m}$., their total length approaching 500 metres. Many of them, especially those taken near the equator, showed a pronounced stratification indicating changes of surface conditions affecting the distribution of plankton organisms. A special feature on our echograms near the regions of divergence at the surface were diffusely reflecting layers in a depth of 100-250 metres, presumably fish shoals or masses of other pelagic organisms. Attempts to sample these reflecting layers failed for lack of suitable gear.

Landings made at different ocean islands afforded opportunities for making botanical collections and photographic studies of animals and plants.

Measurements of the thickness of sediment by means of recording echoes from exploding depth charges were made frequently along our course. Except near Panama, where higher values were found, no reflecting layers could be discovered below the 1,000-ft. level, in striking contrast with the much deeper echoes found in the Mediterranean and in the open Atlantic Ocean.

After proceeding through the Sunda Archipelago to Soerabaya, raising sediment cores displaying volcanic ash layers and taking hydrographic soundings under way, the expedition started on its cruise into the Indian Ocean on February 18, 1948, from Bali. Strong winds, approaching hurricane force in the squalls, made work impossible during the first week; but afterwards weather conditions were ideal. Such was not the case, however, with the state of the sea bottom, the ruggedness of which made both core sempling and measurements of sediment thickness precarious. The number of cores raised from the eastern Indian Ocean was therefore unexpectedly small-a total length of only 60 metres-and the loss of instruments was relatively heavy.

An interesting feature on our echograms was a perfectly flat bottom at a depth of about 4,300 metres, which extended for several hundred nautical miles from near the equator towards the coast of Ceylon, where the depth over long stretches did not vary by more than a few fathoms. Here the core sampler was broken in two, proving that the bottom was hard, with very thin cover of sediment (an extensive lava bed ?).

Following from Colombo a course towards the south-south-east, we again passed over the southern hemisphere, afterwards setting course for the Seychelles. The cores raised from the western Indian 